\title{
Role of sonication time on thermal behaviour and dynamic mechanical analysis of NiZn ferrite incorporated PLA/LNR nanocomposite
}

\author{
DALILA SHAHDAN ${ }^{1}$, MOAYAD HUSEIN FLAIFEL ${ }^{2}$, RUEY SHAN CHEN ${ }^{1, *}$, SAHRIM AHMAD $^{1}$ \\ and AZIZ HASSAN ${ }^{3}$ \\ ${ }^{1}$ School of Applied Physics, Faculty of Science and Technology, The National University of Malaysia, 43600 Bangi, \\ Selangor, Malaysia \\ ${ }^{2}$ Department of Physics, College of Science, University of Damman, Al Rayyan, Damman 32256, \\ Kingdom of Saudi Arabia \\ ${ }^{3}$ Department of Chemistry, Faculty of Science, University of Malaya, 50603 Kuala Lumpur, Malaysia \\ *Author for correspondence (rueyshanchen@ hotmail.com)
}

MS received 3 April 2017; accepted 1 January 2019; published online 7 March 2019

\begin{abstract}
The investigation on thermal properties of polylactic acid/liquid natural rubber (PLA/LNR) blend embedded with nickel zinc (NiZn) ferrite nanoparticles at various loading (1-5 wt\%) and treated with different ultrasonication time (1-2 h) is the main core of this study. The novel NiZn nanocomposite based on the matrix of PLA:LNR with a ratio of 90:10 was fabricated via melt blending technique with the aids of ultrasonication. The effects of nanofiller loading and ultrasonic treatment on nanocomposite were examined by scanning electron microscopy, differential scanning calorimetry and dynamic mechanical analyser. The results revealed that the thermal properties of PLA/LNR matrix have improved with incorporation of nanoparticles in which improvement was observed until an optimum level at $4 \mathrm{wt} \% \mathrm{NiZn}$ ferrite within $1 \mathrm{~h}$ of ultrasonic treatment. The optimum ultrasonication for $1 \mathrm{~h}$ is believed to be sufficient to promote a good dispersion of NiZn ferrite nanoparticles within the PLA/LNR and in order to enhance the thermal stability, which makes it potentially to be used in electronic applications.
\end{abstract}

Keywords. Polymer-matrix composites (PMCs); nanoparticles; melt blending; thermal properties; ultrasonics.

\section{Introduction}

The recent advent of nanoparticles has gained interest in enhancing the properties of matrix in producing polymermatrix nanocomposites (PMNCs), for instances, carbon nanotube (CNT) [1], nanofibres [2,3], organo-montmorillonite [4] etc. In this study, NiZn ferrite nanoparticles were selected as nanofillers owing to its potentially effective filler in polymer matrices due to their mechanical hardness, chemical stability, magnetically soft behaviour, high electrical resistivity and great thermal conductivity properties [5]. However, there is a great challenge in the field of nanocomposite for researchers to get a homogeneous distribution of reinforcement within the entire matrix [3]. The large surface area (high-aspect ratio) possessed by the nanoparticles could easily promote the particle-particle interactions, especially when high nanofiller loading is used, which thereby leads to a subsequent agglomeration of nanoparticles [6].

Controlling the dispersion of nanoparticle in a polymeric matrix is a major challenge and is the key to attain drastic improvement of polymer nanocomposites' properties [7]. In order to minimize the agglomeration problem, the method of mixing or incorporating the nanoparticles into the polymer matrix is one of the important factors to achieve good distribution and dispersion of nanofiller in the resultant composite. The use of ultrasonic treatment with the purpose to enhance the distribution of nanoparticles within polymer matrix has been used in several case studies $[6,8,9]$. Tarawneh et al (2013) reported that a good dispersion of multi-walled carbon nanotubes (MWCNTs) in the matrix of thermoplastic natural rubber (TPNR) was obtained with the incorporation of ultrasonication treatment. Besides, there are very few studies on using ultrasonic treatment to improve nanoparticles dispersion in polymer matrix, especially research on incorporating liquid natural rubber (LNR) and nanoparticles with ultrasonic treatment [10-13].

Thermal stability of polymer nanocomposites (in this study using magnetic nanofiller) is important to investigate the potential use of the polymer nanocomposites as localized heat surfaces for thermal processing of polymer and further exploration for potential application $[14,15]$. Differential scanning calorimetry (DSC) can be used for determining glass transition temperature $\left(T_{\mathrm{g}}\right)$, melting temperature $\left(T_{\mathrm{m}}\right)$ and crystallization temperature $\left(T_{\mathrm{cc}}\right)$ in relation to the composition and preparation method [16]. Dynamic mechanical analysis (DMA) is another important technique, which can be used 
to study the effect of temperature on the properties of composite materials [17]. It also helps to study the polymer miscibility in polymer blends and also measure the $T_{\mathrm{g}}$ of the polymers [18]. Besides that, there are three important values that can be obtained in order to understand further on the viscoelastic behaviour of the nanocomposites that are under the effect of temperature, which are storage modulus $\left(E^{\prime}\right)$, loss modulus $\left(E^{\prime \prime}\right)$ and tangent delta $(\tan \delta)$ are intercorrelated through the mathematical expression given by tan $\delta=E^{\prime \prime} / E^{\prime}[19]$.

Despite many reported research works regarding the fabrication and properties of PMNCs [19,20], this study focuses specifically on the preparation of PLA/LNR/NiZn ferrite nanocomposite in which the mixture of LNR and NiZn ferrite powders was subjected to a vigorous ultrasonic bath before the compounding process. In this current work, the effect of NiZn ferrite loadings and ultrasonic treatment times on the thermal behaviour and morphological observation of PLA/LNR/NiZn nanocomposite samples were evaluated.

\section{Materials and methods}

\subsection{Raw materials}

The thermoplastic resin used in this study was a commercial polylactic acid (PLA) of Natureworks IngeoTM Biopolymer 3251D with a density of $1.24 \mathrm{~g} \mathrm{~cm}^{-3}$ and melt flow index of $30-40 \mathrm{~g} / 10 \mathrm{~min}$ for $190^{\circ} \mathrm{C} / 2.16 \mathrm{~kg}$, and was supplied by Unic Technology Ltd, China. SMR-L grade natural rubber (NR) was obtained from Malaysian Rubber Board (MRB). LNR was self-synthesized by photosensitized chemical degradation/oxidation technique using the raw NR with $50 \%$ of pure NR. Nickel zinc (NiZn) ferrite nanoparticles powder with the chemical formula of $\mathrm{Ni}_{0.5} \mathrm{Zn}_{0.5} \mathrm{Fe}_{2} \mathrm{O}_{4}$, purity of $98.5 \%$ and average particle size of $10-30 \mathrm{~nm}$ was obtained from Nanostructured \& Amorphous Materials Inc, USA. Prior to compounding, the PLA was oven-dried at $100^{\circ} \mathrm{C}$ for $24 \mathrm{~h}$ to remove moisture trapped in the PLA.

\subsection{Composites preparation}

PLA/LNR blend was prepared using an internal mixer machine (Haake Rheomix 600P) at $180^{\circ} \mathrm{C}$ with rotor speed of $100 \mathrm{rpm}$ for a complete mixing time of $15 \mathrm{~min}$. Indirect mixing technique (IDT) was applied in order to fabricate the nanocomposites, which involved a pre-mixing of NiZn ferrite nanoparticles and LNR via an ultrasonic treatment (ultrasonic instrument; Wiseclean at $75^{\circ} \mathrm{C}$ with power of $290 \mathrm{~W}$ and frequency of $50 \mathrm{~Hz}$ ) for 0,1 and $2 \mathrm{~h}$ before melt blending with PLA pellets in the internal mixer. The PLA:LNR was fixed in ratio of 90:10, and the NiZn ferrite nanoparticles were varied at $1-5 \mathrm{wt} \%$. The compounding process was started by inserting the PLA pellets into the mixer for about $3 \mathrm{~min}$, and followed by the pre-mixture of LNR and NiZn ferrite nanoparticles. The whole mixing process took $15 \mathrm{~min}$ to complete.
The compounded granules were taken to make composite panels using hot-press compression moulding. The platens temperature of $190^{\circ} \mathrm{C}$ was applied and the period of compression process was $15 \mathrm{~min}$ with preheating for $4 \mathrm{~min}$, venting for $4 \mathrm{~min}$, full pressing for $3 \mathrm{~min}$ and cold pressing process were set for $5 \mathrm{~min}$.

\subsection{Morphological behaviour of NiZn ferrite-filled nanocomposites}

The fractured surface morphology of nanocomposites was examined using scanning electron microscopy (SEM) (model VPSEM Philips XL 30). Prior to SEM observation, the tensilefractured surface was coated with gold in order to avoid electrostatic charging during SEM observation.

\subsection{Determination of thermal properties}

DSC (Mettler Toledo $822^{\mathrm{e}}$ ) was used to determine the glass transition temperature $\left(T_{\mathrm{g}}\right)$, crystallization temperature $\left(T_{\mathrm{cc}}\right)$ and melting temperature $\left(T_{\mathrm{m}}\right)$ of nanocomposites. The samples were tested in the temperature range from 0 to $250^{\circ} \mathrm{C}$ at $10^{\circ} \mathrm{C} \mathrm{min}^{-1}$ heating rate under nitrogen gas pressure.

The effect of temperature on the viscoelastic properties (storage modulus $E^{\prime}$, loss modulus $E^{\prime \prime}$ and loss tangent $\tan \delta$ ) of PLA/LNR nanocomposite samples with different filler loadings was investigated using dynamic mechanical analyser (DMA model Q800) that is undergoing cyclic stress. The specimens were subjected to three-point bending mode with a span of $50 \mathrm{~mm}$. The measurements were carried out in the temperature range of $30-150^{\circ} \mathrm{C}$ with scan rate of $10^{\circ} \mathrm{C} \mathrm{min}{ }^{-1}$ under a fixed frequency of $1 \mathrm{~Hz}$.

\section{Results and discussion}

\subsection{Morphological behaviour analysed by SEM}

The surface morphologies of unfilled PLA/LNR and PLA/ LNR/NiZn nanocomposite samples are displayed in figure 1. Figure 1a shows a porous PLA/LNR blend with lots of big holes (as shown in the red circle), which indicates the presence of rubber particles in the PLA matrix. A similar observation was reported in previous studies $[12,21]$ on PLA/LNR as compared with solid morphology structure shown in PLA [21]. Figure $1 \mathrm{~b}-\mathrm{g}$ shows surface morphologies with less porosity where lesser and smaller holes were observed as compared with figure 1a. This observation suggested the filling of holes presented in PLA/LNR matrix by the added nanoparticles such as nanoclay [21], CNTs [12] and NiZn ferrite nanoparticles in this study. The presence of NiZn ferrite nanoparticles can be seen and distinguished by the bright and sphericallike shape phases in which it is expected to be embedded in a polymer matrix or afloat when the NiZn ferrite loading is higher (as shown in figure $1 \mathrm{c}$, e and $\mathrm{g}$ by comparing with figure $1 \mathrm{~b}, \mathrm{~d}$ and $\mathrm{f}$ ). The most compact morphologies (with the 

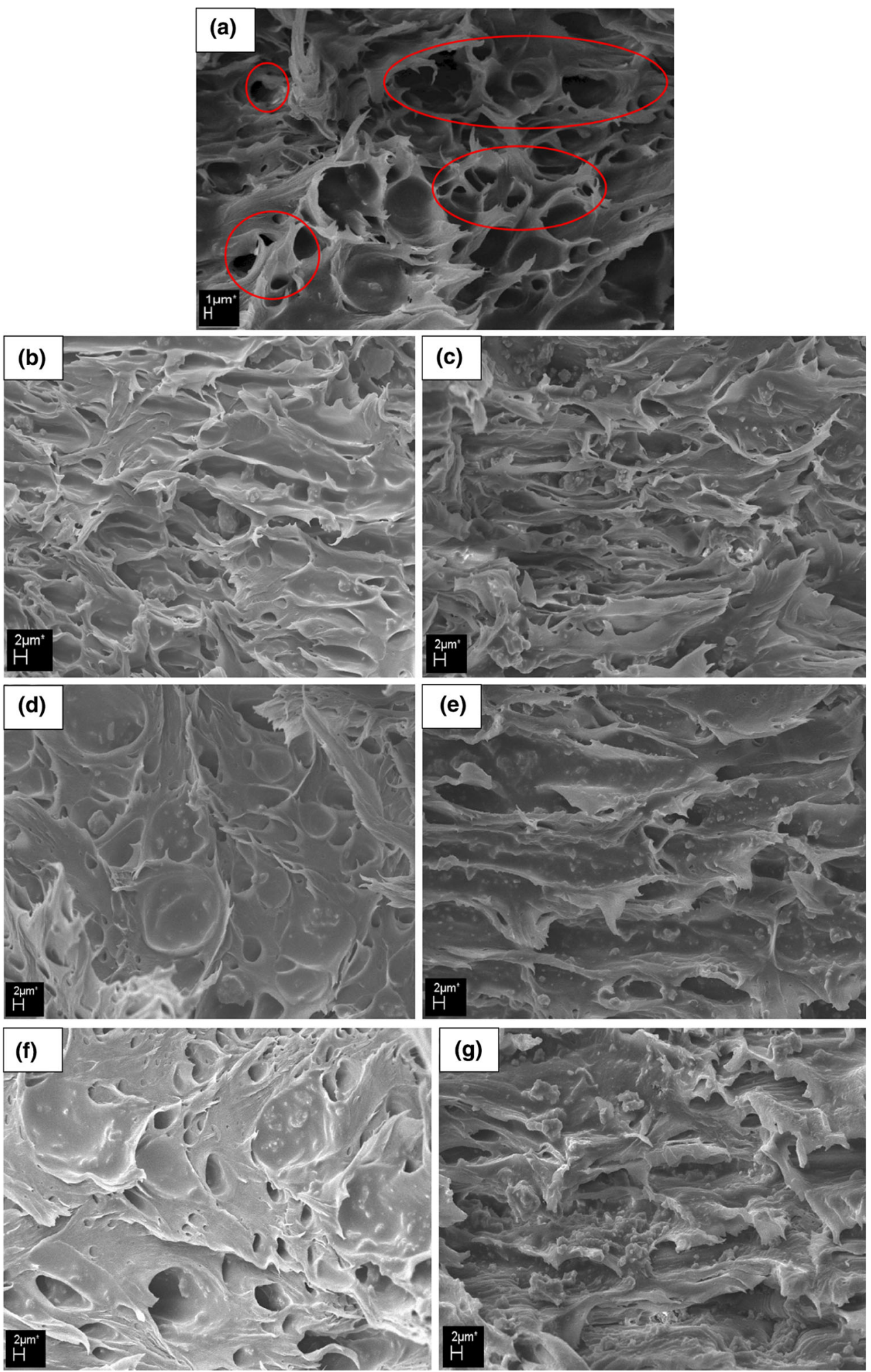

Figure 1. SEM image of (a) pure PLA/LNR and PLA/LNR/NiZn ferrite nanocomposite at 2 wt\% NiZn ferrite (b) without ultrasonic, (d) $1 \mathrm{~h}$ ultrasonic, (f) $2 \mathrm{~h}$ ultrasonic and $4 \mathrm{wt} \%$ NiZn ferrite (c) without ultrasonic, (e) $1 \mathrm{~h}$ ultrasonic, (g) $2 \mathrm{~h}$ ultrasonic. 
least amount of holes) were displayed by the PLA/LNR/NiZn ferrite nanocomposites treated with $1 \mathrm{~h}$ ultrasonic (figure $1 \mathrm{~d}$ and e), followed by nanocomposites treated with $2 \mathrm{~h}$ ultrasonic (figure $1 \mathrm{f}$ and $\mathrm{g}$ ) and lastly the one without ultrasonic treatment (figure $1 \mathrm{~b}$ and $\mathrm{c}$ ). This phenomenon is greatly related to dispersion and distribution of NiZn ferrite in the PLA/LNR blend matrix.

Figure 1d-g shows the morphologies of nanocomposite samples with the aid of 1 and $2 \mathrm{~h}$ ultrasonic treatment at different $1000 \times$ magnification, respectively. The ultrasonic treatment was applied to obtain the more homogeneous NiZn ferrite filler dispersed well in the PLA/LNR matrix blend. Generally, it can be seen here that NiZn ferrite dispersion in the matrix was comparatively good for nanocomposite samples with 1 and $2 \mathrm{~h}$ of ultrasonic treatment (figure $1 \mathrm{~d}-\mathrm{g}$ ) than the samples without ultrasonic treatment (figure $1 \mathrm{~b}$ and $\mathrm{c}$ ). The result of good dispersion was because of the good interaction and strong interfacial bonding between nanoparticles and matrix in which the created uniform crosslinking network in the matrix is crucial for efficiently transferring stress from the matrix to the fillers, as agreed in the study of Tarawneh et al [9].

By comparing 1 and $2 \mathrm{~h}$ ultrasonication for $4 \mathrm{wt} \% \mathrm{NiZn}$ ferrite filled nanocomposites, it was found that there were more voids (figure 1f) and larger agglomerations (figure 1g) in the latter condition (compared with figure $1 \mathrm{~d}$ and e, respectively). Yuhana et al [22] stated that the longer time of ultrasonic treatment may cause bubbles to form in the liquid mixture (LNR in this case) and thus, leaving voids in the composite samples. The formation of agglomeration in the nanocomposites resulted from the self-entanglement among the nanoparticles due to the high collision frequency in the polymer matrix when the sonication time was too long [9].
Therefore, controlling the period of ultrasonic treatment is very important to obtain a good dispersion of filler in the matrix. If the sonication time is at proper level, $1 \mathrm{~h}$ in this study, the nanoparticles can be dispersed uniformly where the nanoparticles obtained the energy in the vibration form as provided during the sonication treatment that allowing the nanoparticles to escape from the surrounding restrained polymer and to transfer the stress more efficiently. In the condition of short ultrasonic time ( $<1 \mathrm{~h}$ in this study), the sound wave energy is insufficient to scatter the nanofiller and cause a good and homogeneous dispersion of nanofillers. However, if the treatment time is too long, it will cause the formation of nanofiller clusters [9].

\subsection{Thermal behaviour determined by DSC}

The effects of NiZn ferrite loading and ultrasonic treatment period on the thermal transitions of PLA/LNR nanocomposites are demonstrated in figures 2 and 3, respectively. The DSC results of $T_{\mathrm{g}}, T_{\mathrm{m}}$ and $T_{\mathrm{cc}}$ values for the neat PLA/LNR and PLA/LNR/NiZn nanocomposites are reported in table 1. As shown by the DSC curves in figures 2 and 3, there were three obvious peaks that appeared over the temperature range of $0-250^{\circ} \mathrm{C}$ : two exothermic peaks occurred at $45-70$ and $150-180^{\circ} \mathrm{C}$, which indicate $T_{\mathrm{g}}$ and $T_{\mathrm{m}}$, respectively; an endothermic peak located at $74-95^{\circ} \mathrm{C}$, which corresponds to $T_{\text {cc }}$. Generally, the incorporation of NiZn ferrite nanofiller into PLA/LNR was found to affect the position of $T_{\mathrm{g}}, T_{\mathrm{m}}$ and $T_{\mathrm{cc}}$ of the resultant nanocomposite specimens. For the neat PLA/LNR sample, $T_{\mathrm{g}}$ was recorded at $54.81^{\circ} \mathrm{C}$. When the NiZn ferrite was added, $T_{\mathrm{g}}$ increased up to an optimum level (on an average about $60^{\circ} \mathrm{C}$ ) at 3 or $4 \mathrm{wt} \%$ of $\mathrm{NiZn}$ ferrite for those nanocomposite irrespective of ultrasonic

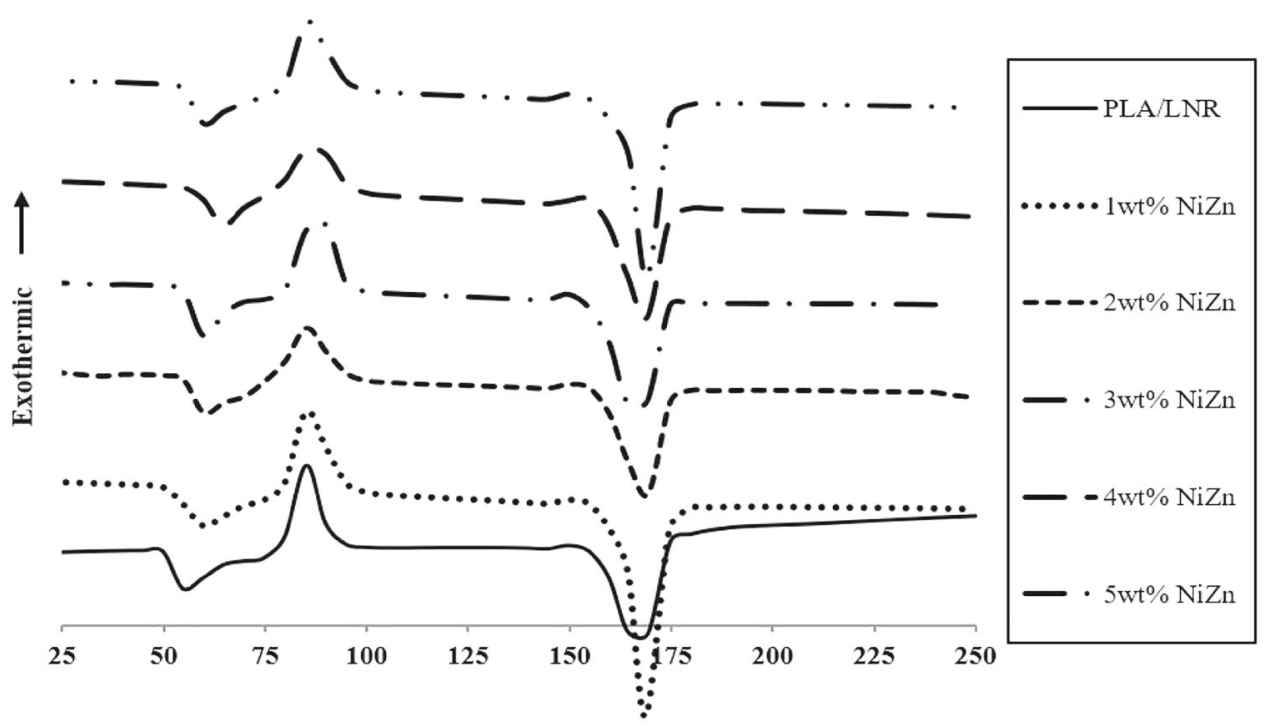

Temperature $/{ }^{\circ} \mathrm{C}$

Figure 2. DSC curves of PLA/LNR and PLA/LNR/NiZn ferrite nanocomposites containing various (1-5 wt $\%)$ NiZn ferrite loading without ultrasonic treatment. 


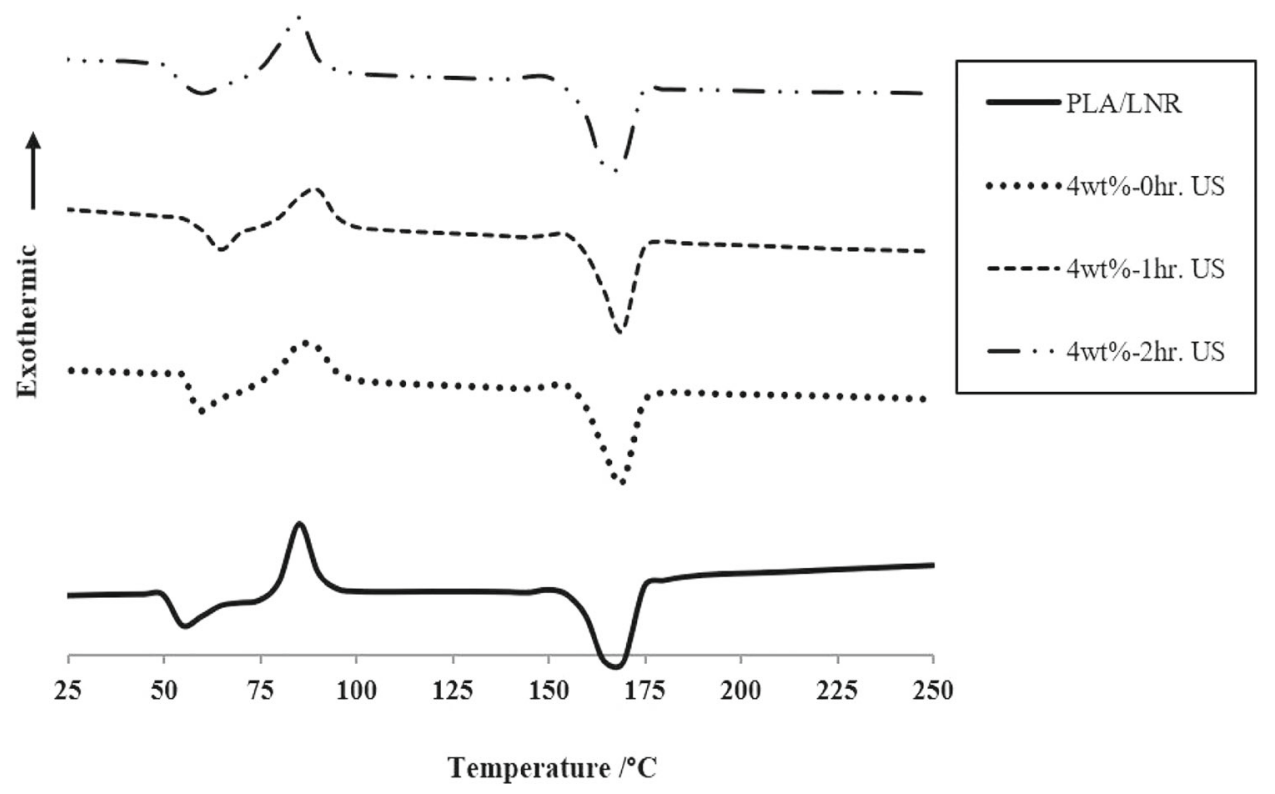

Figure 3. DSC curves of PLA/LNR nanocomposites with different ultrasonic time at constant NiZn ferrite loading. Note: US represents ultrasonic.

Table 1. Values for $T_{\mathrm{g}}, T_{\mathrm{m}}$ and $T_{\mathrm{cc}}$ specimens at different ultrasonication time.

\begin{tabular}{lccc}
\hline Samples & $T_{\mathrm{g}}\left({ }^{\circ} \mathrm{C}\right)$ & $T_{\mathrm{cc}}\left({ }^{\circ} \mathrm{C}\right)$ & $T_{\mathrm{m}}\left({ }^{\circ} \mathrm{C}\right)$ \\
\hline PLA/LNR & 54.81 & 85.22 & 169.49 \\
Without ultrasonic & & & \\
1 wt\% NiZn & 53.52 & 79.83 & 168.68 \\
2 wt\% NiZn & 55.40 & 79.91 & 169.26 \\
3 wt\% NiZn & 59.74 & 85.01 & 169.24 \\
4 wt\% NiZn & 58.99 & 84.95 & 164.24 \\
5 wt\% NiZn & 55.63 & 79.85 & 168.9 \\
1 h ultrasonic & & & \\
1 wt\% NiZn & 52.97 & 85.07 & 169.14 \\
2 wt\% NiZn & 54.81 & 84.99 & 164.35 \\
3 wt\% NiZn & 59.82 & 85.04 & 169.42 \\
4 wt\% NiZn & 64.69 & 89.92 & 169.06 \\
5 wt\% NiZn & 59.69 & 87.9 & 164.15 \\
2 h ultrasonic & & & \\
1 wt\% NiZn & 54.78 & 79.90 & 169.05 \\
2 wt\% NiZn & 54.91 & 79.93 & 169.30 \\
3 wt\% NiZn & 57.29 & 79.99 & 164.26 \\
4 wt\% NiZn & 59.71 & 89.80 & 169.14 \\
5 wt\% NiZn & 55.36 & 85.02 & 169.41 \\
\hline
\end{tabular}

treatment period. As reported in literature, the incorporation of nanoparticles such as NiZn ferrite in this case could affect the relaxation process. This relaxation process can be associated with a ductile-to-brittle transition, and the dramatic reduction of the local mobility of the polymer linkages [23], thereby resulted in the increase of $T_{\mathrm{g}}$ values. However, further increasing the NiZn ferrite loading which were more than $3 \mathrm{wt} \%$ for the nanocomposites prepared without ultrasonic treatment and $4 \mathrm{wt} \%$ for those treated ultrasonically, it showed downward trends in the $T_{\mathrm{g}}$ value. This is because the inhomogeneity of the filler matrix and conglomerates in the NiZn network caused the defects, which allowed the macromolecules to move easily [24].

Ultrasonic treatment was applied for about 1 and $2 \mathrm{~h}$ to obtain a better and homogeneous dispersion of NiZn ferrite within the PLA/LNR matrix. This objective was achieved as can be seen in table $1, T_{\mathrm{g}}$ values obtained for specimens prepared using ultrasonic treatment were significantly higher as compared with the untreated samples (without ultrasonic treatment). The highest increment of $T_{\mathrm{g}}$ values for specimens using ultrasonic treatment (both 1 and $2 \mathrm{~h}$ ) was attained at $4 \mathrm{wt} \%$ of NiZn ferrite, which was higher loading than those without ultrasonic treatment only at $3 \mathrm{wt} \%$ of NiZn. As reported in literature, the $T_{\mathrm{g}}$ of the polymer system is closely related to the molecular movement restrictions whether reducing the extent of freedom or giving higher degree of crosslinking [25]. The increase of $T_{\mathrm{g}}$ in this study was because of the uniform nanofiller dispersion in the matrix and the improved polymer chains-nanoparticles interactions with the aids of ultrasonic treatment which resulted in a decrease in the movement of macromolecular chains.

As shown in table 1, the nanocomposites with 4 and $5 \mathrm{wt} \%$ of NiZn ferrite using ultrasonic treatment for $1 \mathrm{~h}$ showed the highest $T_{\mathrm{g}}$. This is attributed to the homogeneous dispersion of nanofiller in the $1 \mathrm{~h}$ ultrasonic-treated samples, shown in figure 1e, as compared with the sample without ultrasonic and with $2 \mathrm{~h}$ ultrasonic treatment (inhomogeneous morphological structure in figure $1 \mathrm{c}$ and $\mathrm{g}$ ).

$T_{\mathrm{cc}}$ is defined as the temperature at which the arrangement and formation of crystalline regions takes place in a material [12]. The cold crystallization peak of the neat PLA/LNR 
occurred at $85.22^{\circ} \mathrm{C}$ as given in table 1 . Interestingly, this value is different with the previous studies $[12,21]$, which reported that the $T_{\mathrm{cc}}$ of PLA/LNR was $123-124^{\circ} \mathrm{C}$. However, it is somewhere close to the $T_{\mathrm{cc}}$ of neat PLA $\left(86.3^{\circ} \mathrm{C}\right)$ as shown in literature [21]. This phenomenon might be because of the different characteristics in the self-synthesized LNR in each experiment. Generally, the $T_{\mathrm{cc}}$ of PLA/LNR/NiZn ferrite nanocomposites was shifted to lower temperatures, with an exception of $4 \mathrm{wt} \%$ NiZn ferrite nanocomposites with ultrasonic treatment, but there is no specific trend with respect to nanofiller loading. The reduction of $T_{\mathrm{cc}}$ implies that NiZn ferrite nanoparticles have the ability to act as nucleating agent that can promote the initial crystallization of PLA by inducing the heterogeneous nucleation site of PLA crystallization [12,21].

The endothermic peak presented after the $T_{\mathrm{g}}$, which is $T_{\mathrm{m}}$ represents the excess enthalpy relaxation as a result of thermal and mechanical actions of the PLA/LNR and PLA/LNR nanocomposites during melt blending process and hot pressing [24]. The addition of NiZn ferrite loading slightly reduced the $T_{\mathrm{m}}$ but the changes do not show specific and significant trend for the PLA/LNR/NiZn nanocomposites (refer table 1). This finding is consistent with other studies on PLA/LNR/nanoclay [21], which reported the remarkable downward trend in $T_{\mathrm{m}}$ on the incorporation of nanoclay.

\subsection{Dynamic mechanical behaviour}

From DMA analysis, three important information could be obtained, those are storage modulus, loss modulus and $\tan \delta$. Storage modulus $\left(E^{\prime}\right)$ evaluation designates the material's ability to keep the energy of the external forces before the deformation of permanent strain [26]. In general, $E^{\prime}$ is closely associated with the elastic and stiffness property of a certain material [27]. E' can provide interpretation in the molecular basis of the mechanical behaviour of materials as the feature that are sensitive to the structural changes for instance, the structure of the interface bonding between the matrix and filler $[23,24]$. Meanwhile, loss modulus $\left(E^{\prime \prime}\right)$ can be considered as a good indication for the material's ability to release energy, which is unrecoverable in the system. Generally, $E^{\prime \prime}$ is closely related with the viscous behaviour and impact resistance of one material. In addition, $\tan \delta$ is defined as the ratio of the loss moduli to storage moduli. It shows the nature of the materials impact associated with the nature of impact resistance of a material [26]. Figure 4 illustrates the effects of NiZn loading on the $E^{\prime}, E^{\prime \prime}$ and $\tan \delta$ of PLA/LNR/NiZn nanocomposites without ultrasonic treatment. Meanwhile, the effects of ultrasonic time on the $E^{\prime}, E^{\prime \prime}$ and $\tan \delta$ of PLA/LNR nanocomposites containing $4 \mathrm{wt} \% \mathrm{NiZn}$ are presented in figure 5 .

As depicted in figure $4 \mathrm{a}, E^{\prime}$ of the neat PLA/LNR sample decreased slowly at low temperatures between 30 and $40^{\circ} \mathrm{C}$, but when the temperature reached close to $50^{\circ} \mathrm{C}$, the $E^{\prime}$ decreased dramatically. This was closely related to the $T_{\mathrm{g}}$ of the polymer. It can also be shown that the $E^{\prime}$ increased when the loading of the NiZn ferrite increased. At $30^{\circ} \mathrm{C}, E^{\prime}$
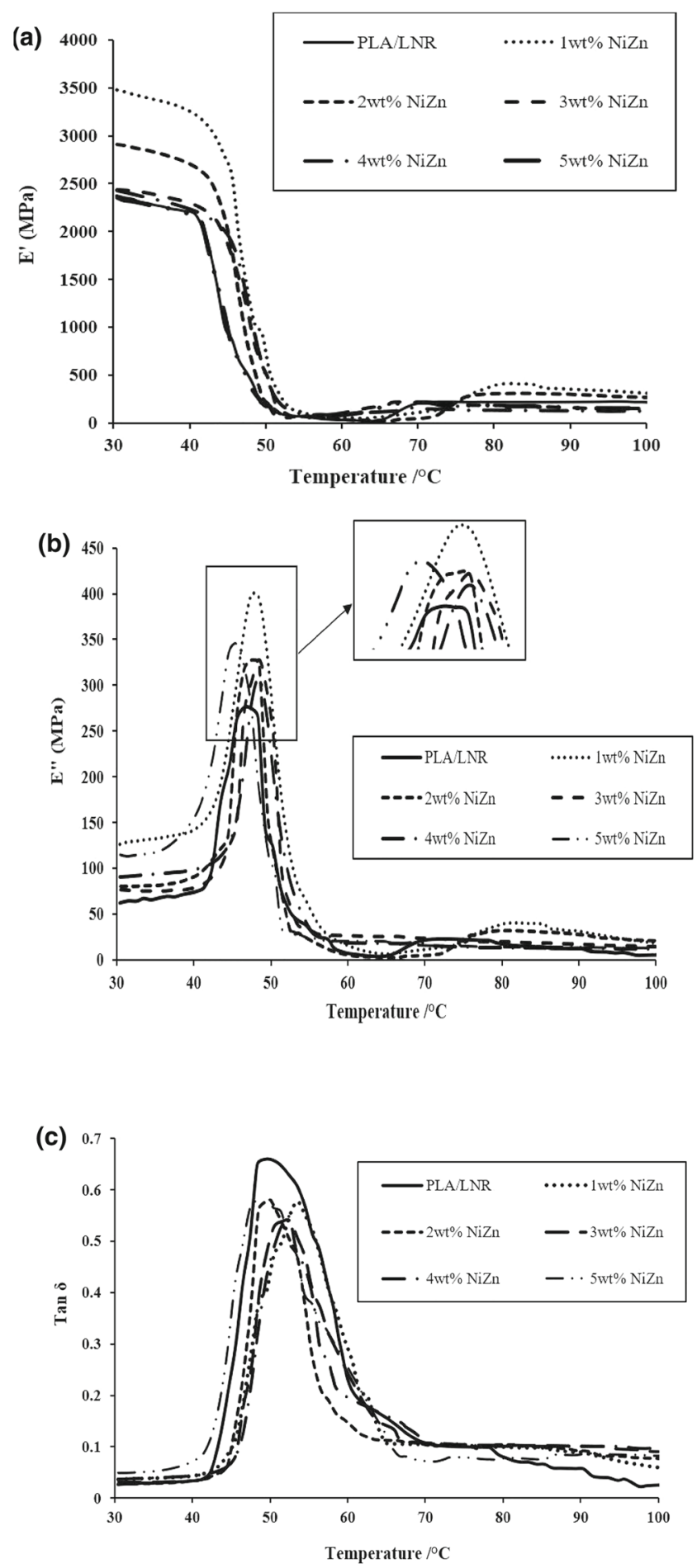

Figure 4. (a) Storage modulus, (b) loss modulus and (c) $\tan \delta$ of PLA/LNR and PLA/LNR/NiZn nanocomposites without ultrasonic treatment.

of PLA/LNR is $2377.67 \mathrm{MPa}$, the highest storage moduli was achieved at $1 \mathrm{wt} \%$ of filler with $3479.31 \mathrm{MPa}$, followed by 2 wt $\%$ of NiZn ferrite with $2909.93 \mathrm{MPa}$. Comparing with neat PLA/LNR, specimens with 3-4 wt\% NiZn ferrite showed a slight increase in $E^{\prime}$. At $5 \mathrm{wt} \%$ NiZn ferrite, $E^{\prime}$ showed the 


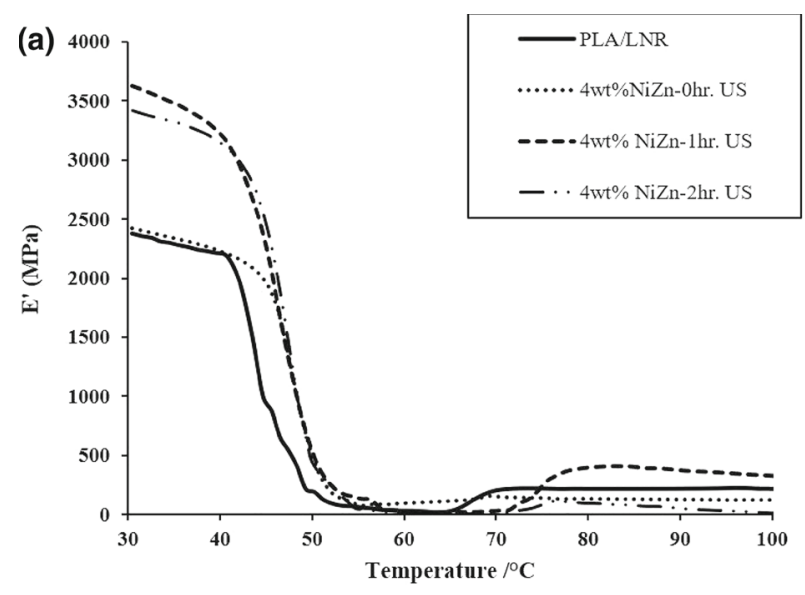

(b)
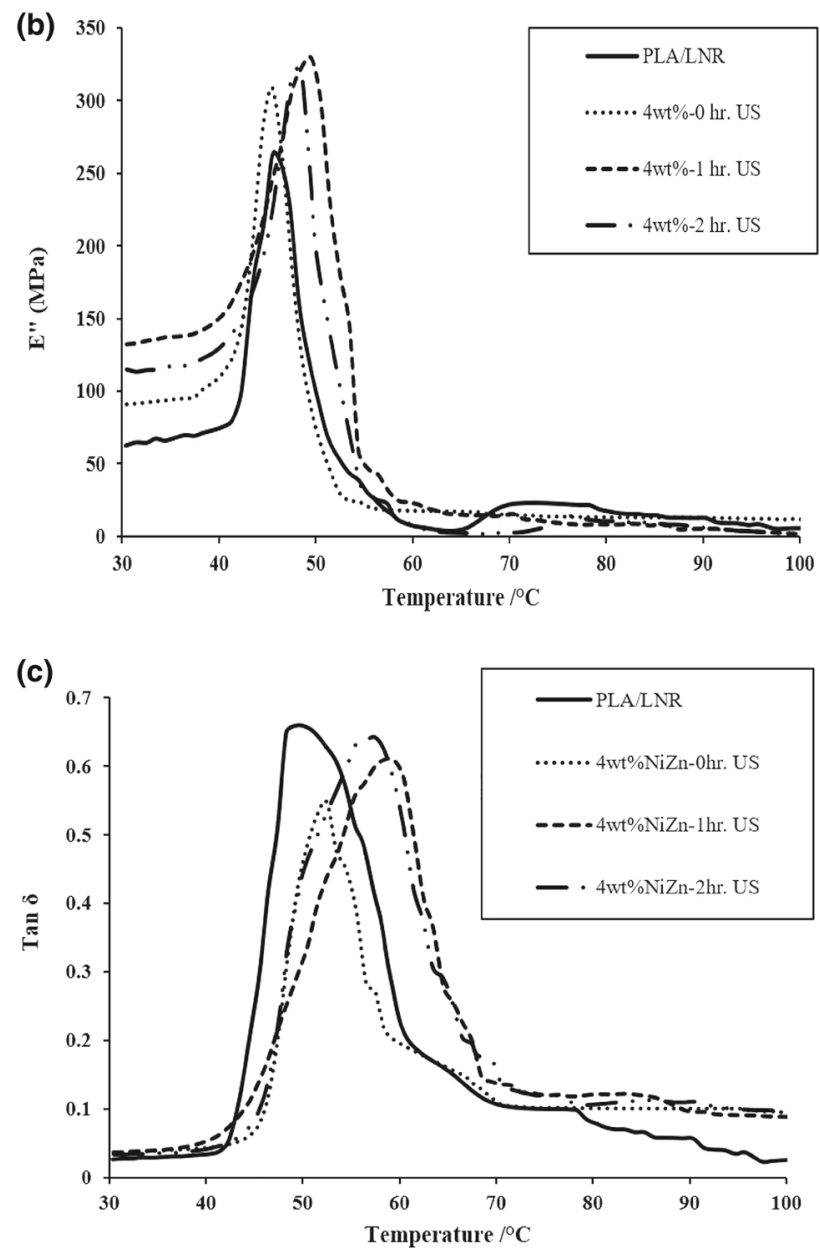

Figure 5. (a) Storage modulus, (b) loss modulus and (c) $\tan \delta$ for PLA/LNR and its nanocomposites with $4 \mathrm{wt} \% \mathrm{NiZn}$ at different ultrasonic time.

lowest value. The improvement of storage modulus with the introduction of fillers has been reported by Flaifel et al [19], who stated the reason behind the enhancement of the stiffness could be explained through the reinforcement effect imparted by the nanofiller and the possible great matrix-nanofiller interfacial interactions to allow more stress distribution.
Figure $4 \mathrm{~b}$ depicts the effect of NiZn ferrite loading and temperature rise on $E^{\prime \prime}$ of composite. The value of $E^{\prime \prime}$ for all samples was found to increase in the temperature range from 40 to $50^{\circ} \mathrm{C}$ (maximum $E^{\prime \prime}$ ) and decrease on further increasing the temperature. It is visible that these maximum values of $E^{\prime \prime}$ of the samples showed a decreasing trend with the increasing of filler loading as similarly observed in [26], in which suggesting higher damping characteristics of samples with lower filler loading compared with higher filler loading. However, it can be observed that the loss modulus peak occurred slightly lower than $T_{\mathrm{g}}$ which might be due to the relaxation process. By incorporating NiZn ferrite from 1 to $4 \mathrm{wt} \%$ into PLA/LNR, this peak shifted slightly to the right. Meanwhile, further increasing the NiZn ferrite loading at $5 \mathrm{wt} \%$ led to a shiftment of the peak to the left in comparison to neat PLA/LNR matrix. This could be due to the over filler-filler interaction induced by the addition of high nanoparticle loading ( $5 \mathrm{wt} \%$ $\mathrm{NiZn}$ ferrite in this study) which resulted in bad dispersion and worst agglomeration. A similar finding was reported in Adilah et al [13], who carried out research studies on CNTs.

Figure $4 \mathrm{c}$ shows the $\tan \delta$ measurement of nanocomposite specimens. A tan $\delta$ peak was observed at $48-54^{\circ} \mathrm{C}$, which corresponded to the $T_{\mathrm{g}}$ of PLA. This peak was found to increase with the addition of NiZn ferrite from 1 to $4 \mathrm{wt} \%$ in the nanocomposites in comparison with the neat PLA/LNR. The increase of $\tan \delta$ was due to the existence of strong interface bonding between filler and matrix, which can be ascribed to the strengthening effect where the nanoparticles restricted the mobility of the amorphous polymeric chains [19].

The graph in figure 5a shows a plot of dynamic mechanical properties of PLA/LNR nanocomposites without and with ultrasonic treatment. The $E^{\prime}$ showed the highest values at room temperature and it decreased with the increasing temperature. At $30^{\circ} \mathrm{C}$, the samples with $4 \mathrm{wt} \% \mathrm{NiZn}$ ferrite prepared using the $1 \mathrm{~h}$ ultrasonic treatment had the highest $E^{\prime}$ value of $3603.56 \mathrm{MPa}$, followed by the specimen with 4 wt\% NiZn ferrite with $2 \mathrm{~h}$ ultrasonic treatment at $E^{\prime}$ value of $3416.33 \mathrm{MPa}$. The nanocomposite material without ultrasonic treatment exhibited a lower $E^{\prime}$ value than those with ultrasonic treatment. However, its value still was higher than the neat PLA/LNR without filler.

Figure $5 \mathrm{~b}$ presents the effect of ultrasonic treatment of NiZn nanofiller and temperature on $E^{\prime \prime}$ of the composites. It can be found that the nanocomposite sample with $1 \mathrm{~h}$ ultrasonic treatment gave the highest loss modulus peak value at the most right position (the highest temperature) as compared with $2 \mathrm{~h}$ ultrasonic treatment and samples without ultrasonic treatment. This indicates the enhancement in the thermal stability of the relaxation process for nanocomposites that underwent $1 \mathrm{~h}$ ultrasonication. In which it means that this period of treatment appeared to be the most effective to disperse the NiZn ferrite within the matrix and so hindering the movement of matrix molecules as a result of strong and homogenous interface between NiZn ferrite and PLA/LNR. On the contrary, as reported by Flaifel et al [19], the bigger agglomeration has a high tendency to be formed when the period of 
ultrasonication was exceeded to the optimum limit $(2 \mathrm{~h}$ in this case) in which this reduced the aspect ratio of filler and restricted the stress transfer in the polymer matrix. The obtained results from DMA supported the previous DSC analysis.

In figure $5 \mathrm{c}$, the $\tan \delta$ peak for nanocomposite materials with ultrasonic treatment shifted more to the right $\left(57-59^{\circ} \mathrm{C}\right)$ as compared with the specimens without ultrasonic treatment $\left(52^{\circ} \mathrm{C}\right)$. This meant that the matrix molecular mobility was limited due to the interaction of stronger interface between NiZn ferrite and PLA matrix using ultrasonic treatment. However, for specimens with $2 \mathrm{~h}$ ultrasonic treatment, it was found that the dynamic mechanical properties nanocomposites decreased as compared with that of $1 \mathrm{~h}$ ultrasonic treatment. Another striking observation is the broadening of the $\tan \delta$ peak occurred for the ultrasonic-treated nanocomposites as compared with those without ultrasonic treatment and PLA/LNR matrix. This was attributed to the action of molecular relaxations at the increased fibre-matrix interfacial regions in the nanocomposites, which promoted the damping of the treated materials $[19,26,28]$.

\section{Conclusions}

Nanocomposites were fabricated by incorporating PLA/LNR with NiZn ferrite nanoparticles using melt blending technique with ultrasonic treatment from 0 to $2 \mathrm{~h}$. SEM images showed that the samples prepared subjected to $1 \mathrm{~h}$ ultrasonic treatment exhibited good and better dispersion of nanofiller in the polymer matrix as compared with samples subjected to $2 \mathrm{~h}$ ultrasonic treatment and without ultrasonic treatment. Thermal analysis of the samples showed an improvement in thermal stability with the addition of nanofiller with the best result achieved at $1 \mathrm{~h}$ ultrasonic treatment. On the contrary, $4 \mathrm{wt} \%$ NiZn ferrite samples of both 1 and $2 \mathrm{~h}$ ultrasonic treatments achieved the optimum improvement in the thermal stability and dynamic mechanical properties in comparison with the untreated samples at only 2 wt $\%$.

\section{Acknowledgements}

The authors gratefully acknowledge the financial support provided by UKM under grant FRGS/1/2014/SG06/UKM/01/2, GUP-2018-107, FRGS/1/2018/STG07/UKM/01/2, GGPM2018-061 and the Ministry of Higher Education Malaysia MyPHD Scholarship Programme for the donation of materials and financial support. We also appreciate the cooperation given by the staff of the Electron Microscopy Unit, UKM during the SEM-utilization experiments.

\section{References}

[1] Tarawneh M A, Ahmad S H J, Rasid R, Yahya S Y, Shamsul B A R, Ehnoum S et al 2011 Sains Malays. 40725

[2] Anuar H and Ahmad Z 2011 Malays. Polym. J. 651

[3] Uddin M F and Sun C-T 2010 in I M Daniel, E E Gdoutos and Y D S Rajapakse (eds) Major accomplishments in composite materials and sandwich structures (Dordrecht: Springer) p 693

[4] Chow W S and Lok S K 2009 J. Therm. Anal. Calorim. 95627

[5] Flaifel M H, Ahmad S H, Abdullah M H and Al-Asbahi B A 2012 Cryogenics $\mathbf{5 2} 523$

[6] Nguyen V S, Rouxel D and Vincent B 2014 Ultrason. Sonochem. 21149

[7] Roy S, Bandyopadhyay D, Karim A and Mukherjee R 2015 Macromolecules 48373

[8] Tarawneh M A, Ahmad S H J, Zarina K A K, Hassan I N, Jiun Y L, Flaifel M H et al 2013 Sains Malays. 42503

[9] Tarawneh M A A, Ahmad S H, EhNoum S and Lau K-T 2012 J. Compos. Mater. 47579

[10] Chen R S, Shahdan D and Ahmad S 2017 Malays. J. Anal. Sci. 211417

[11] Tarawneh M A, Shahdan D and Ahmad S H 2013 J. Nanomater. 20135

[12] Adilah Mat Ali S H A 2016 Adv. Mater. Res. 1133481

[13] Shahdan D, Ahmad S H and Flaifel M H 2013 AIP Conf. Proc. 157175

[14] Chen R S, Mohd Amran N A and Ahmad S 2018 J. Therm. Anal. Calorim. 1131

[15] Hung M-T, Choi O, Ju Y S and Hahn H T 2006 Appl. Phys. Lett. 89023117

[16] Pluta M, Galeski A, Alexandre M, Paul M-A and Dubois P 2002 J. Appl. Polym. Sci. 861497

[17] Manikandan Nair K C, Thomas S and Groeninckx G 2001 Compos. Sci. Technol. 612519

[18] Hassan E, Wei Y, Jiao H and Yu M 2013 J. Fiber Bioeng. Inform. 685

[19] Flaifel M H, Ahmad S H, Hassan A, Bahri S, Tarawneh M A A and Yu L-J 2013 Compos. Part B Eng. 52334

[20] Flaifel M H, Ahmad S H, Abdullah M H, Rasid R, Shaari A H, El-Saleh A A et al 2014 Compos. Sci. Technol. 96103

[21] Bijarimi M, Ahmad S and Rasid R 2013 J. Reinf. Plast. Compos. 321656

[22] Yuhana N Y, Ahmad S and Bahri A R S 2012 Adv. Mater. Sci. Eng. 20125

[23] Bogdanovich A E and Bradford P D 2010 Compos. Part AAPPL S 41230

[24] Yuzay I E, Auras R and Selke S 2010 J. Appl. Polym. Sci. 115 2262

[25] Pötschke P, Fornes T D and Paul D R 2002 Polymer 433247

[26] Chen R S, Ab Ghani M H, Ahmad S, Salleh M N and Tarawneh M A 2015 J. Compos. Mater. 491241

[27] Chen R S, Ahmad S and Gan S 2016 BioResources 118470

[28] Yu L J, Ahmad S, Ing K, Sivanesan A and Moayad H F 2012 Sains Malays. $\mathbf{4 1} 453$ 